\title{
COVID-19 Outbreak and Urban Green Space, Food Security, and Quality of Life: Case of Urban Home Gardens in Kandy, Sri Lanka
}

\author{
Lalitha Dissanayake $^{1 *}$, Sathya Dilini² \\ ${ }^{1}$ Department of Geography, Faculty of Arts, University of Peradeniya, Peradeniya, Sri Lanka \\ ${ }^{2}$ Postgraduate Institute of Agriculture, University of Peradeniya, Peradeniya, Sri Lanka \\ Email: *dissanayakedm12011@gmail.com
}

How to cite this paper: Dissanayake, L., \& Dilini, S. (2020). COVID-19 Outbreak and Urban Green Space, Food Security, and Quality of Life: Case of Urban Home Gardens in Kandy, Sri Lanka. Open Journal of Social Sciences, 8, 185-197.

https://doi.org/10.4236/jss.2020.89013

Received: August 21, 2020

Accepted: September 18, 2020

Published: September 21, 2020

Copyright () 2020 by author(s) and Scientific Research Publishing Inc. This work is licensed under the Creative Commons Attribution International License (CC BY 4.0).

http://creativecommons.org/licenses/by/4.0/

\begin{abstract}
The study was conceptualized to distinguish contribution of urban home gardening towards household food security and quality of life while making greener environment in urban area in the context of country wise curfew during COVID-19 pandemic and challenges arisen with it. Kandy municipal area was selected as study site and questionnaire surveys over prepared grid map and field observations were the principal data collection methods used in this study. Social and physical inputs for gardening as well as material and immaterial outcomes received through the gardening were considered as major parameters in data collection. It is notable that data collected concerning situation before and during the curfew period. Data feeding and analysis were supported through IBM SPSS Statistics 25 software. Social well-being and mental health was highlighted in all three satisfaction levels of high, moderate, and low and is more than that of $50 \%$ from the total recorded responses. Stress release, collective work, family harmonization, exercise, sharing and social cohesion, knowledge and experience, and healthy foods are the outcomes received in the aspect of social well-being and mental health. As they perceive, environmental quality has amended with the outcomes through greening, aesthetic beauty, land management and erosion control, waste management and clean environment. Also, urban dwellers have assured their economic status during the pandemic situation at least fulfilling one or two diets with homemade vegetable products. Still, social well-being and mental health could be prioritized among the benefits received through home gardening; especially during the pandemic situation. Because, awareness and promotion to achieve desired harvest in the urban home gardening is challengeable in the current context. Thus, those aspects should be address in the agricultural policy preparation without compromising livelihood of large scale farmers. So the crop specification for healthy diet can promote by con-
\end{abstract}


tinuation of this home gardening trend with the experience of COVID-19 pandemic. Then only we can fear off during this kind of disastrous situation.

\section{Keywords}

COVID-19, Food Security, Greener Environment, Social Well-Being, Urban Home Gardening

\section{Introduction}

Definition of home garden has a variety of faces attributed to its structural and functional form and perspective of the person who defines it. In the early definitions, home garden was defined as a small-scale food production system which locates adjacent to human settlements (Niñez, 1987). The production of home garden was recognized as a family consumption oriented (Torres, 1988). However, it is not only a food production system in its form and it may consist of different plant types as per the dwellers requirements. Production sharing with neighbors and relations is also possible. Typical home garden is a kind of mixed cropping system. Food security and quality of life is a problematic concern in the tropical low-income countries. Given that, these subsistence farming systems are easy to handle with low input technologies while achieving nutritional security of millions of people in the tropics (Kunhamu, 2013).

Within the context of Sri Lanka, home garden is an inherent part of the landscape and culture for centuries (Pushpakumara et al., 2012). Garden with at least one or two fruit plants, curry essence plants, Jackfruit (Artocarpus heterophyllus) tree, and vegetable is not new in rural home gardens in Sri Lanka. Even, most of the paddy farming communities have no issue about rice (Rice is the staple food in Sri Lanka). Furthermore, gardening was not difficult for rural dwellers as they intrinsically have large space. Typical Kandyan home gardens are rich diverse gardening system and thus it called as Kandyan forest gardens. Nevertheless, the situation is in contrast to the Kandyan urban home gardens. Less diversity and more ornamental form of structure were visible in the Kandyan urban home gardens specifically due to limited garden space and busy lifestyle of urban dwellers (Dissanayake \& Dilini, 2020).

However, discussion about gardening came to the urban life with the COVID-19 outbreak. In fact, COVID-19 is a serious illness and death recorded disease. Anyways, it is really worth to investigate how this sudden unwelcome phenomenon caused to develop home gardening in the context of Sri Lankan COVID-19 facet. Urban life is usually stressful due to crowding, pollution, and noise environment. This sudden outbreak created bit contrast but still stressful environment to the people who reside in these urban areas. Because, country wise curfew made them a kind of prisoners in their houses. All the social relationships external to the family like parties, festivals, meetings, conferences, weddings, sports events, and picnics, etc. all were restricted. Though it was good 
to develop family relationships, it was not good for people's mentality as it extended for a long time. Also, most of the low-income families were severely affected during the situation and even still they felt with huge stress with the loss of their income generation way. It was difficult to afford food materials even for middle- and high-income people due to barriers in the production and distribution procedure. Rush to buy food materials again a problematic about safety during the pandemic scenario. That's how importance of home gardening palingenesis as a way to support household food security, utilize time, ensuring and enhancing family bonds, contributing mental health, health safety with overall contribution to well-being of the people while creating green and healthy natural space. It is important to note here Sri Lankan government initiatives in this attempt. Because, slide encouragement and inputs for gardening were really important in order to direct urban dwellers for gardening.

During the era, what we all are looking for is sustainability in the development process. Because, we have already gone beyond the limits of resource utilization during the development process. Issues are devastative in the urban areas. Urban home gardens can be supported to reach the many goals in nation agreed Sustainable Development Goals (SDG). Eliminate poverty, erase hunger, establish good health and well-being, enforce gender equality, create decent work and economic growth, reduce inequality, mobilize sustainable cities and communities, influence responsible consumption and production, organize climate action, and advance life on land are the goals which possible to support through the enhancing quality of the home gardens in the urban areas. Hence, this outbreak situation can be properly utilized in this sense also.

Within this context, the overall objective of the study was to identify the movements of urban home gardening during COVID-19 outbreak for urban green space, food security, and quality of life.

\section{Methodology}

\subsection{Study Area}

The study was conducted in Kandy city which is called as Maha Nuwara in Sinhala. The meaning encountered as "Greater City" or "Capital" (Wikipedia, 2020). Though capital city was changed later, Kandy has remained as major city in Sri Lanka when it endures as last kingdom of Sri Lanka. People love to select Kandy due to its attractive natural beauty, cultural and religious importance and function as a commercial center. According to the latest count, Kandy city facilitate for 111,701 urban dwellers in the year 2020 (World Population Review, 2020). The city area configured within 25.1 sq.km of an area (Dissanayake, 2016). Noticeable issues in the city are environmental pollution with acute air pollution and water pollution issues, green cover reduction, and land degradation (Premasiri et al., 2012; Dissanayake et al., 2019; Fernando \& Gunawardena, 2016). In this sense, there is an importance of select this site as a case to study consequences of COVID-19 outbreak to tackle afore mentioned challenges. The 
map of Kandy municipal area is shown in Figure 1.

\subsection{Conceptual Framework}

The study designed to capture the trends of urban home gardens during COVID-19 outbreak. Number of COVID-19 incidents recorded were divided into three phases as detection, early responses, and intervention. As it indicates in Figure 2, home gardening has stood up as a strategic activity to minimize the risk instigated by COVID-19 pandemic. Accordingly, it was assumed that garden setup and development as well as its outcomes achieved during curfew period in early response and intervention phases.

\subsection{Data Collection and Analysis}

Questionnaire survey was conducted during July, 2020 in Kandy Municipal area going through grid system. Grid map was prepared covering the area belongs to municipality placing $2 \times 2$ sq.km grids. Municipal council area spread-out over sixteen grids. Questionnaire survey was conducted as it represents 6 samples from each grid which covers more than $50 \%$ of area and 3 samples were taken from grids which covers less than $50 \%$ of area in Kandy municipality. Figure 1
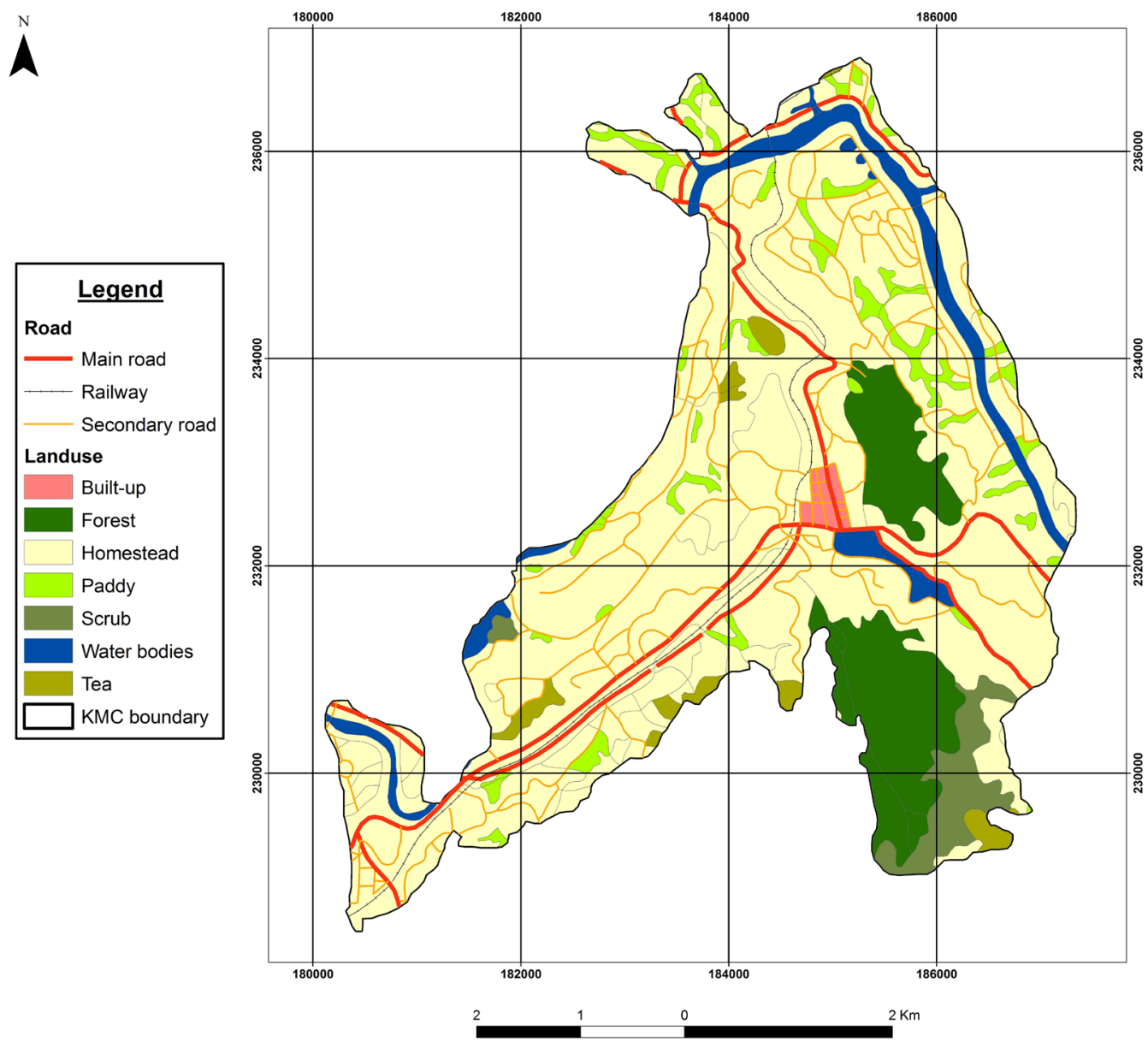

Figure 1. The map of Kandy Municipality. 


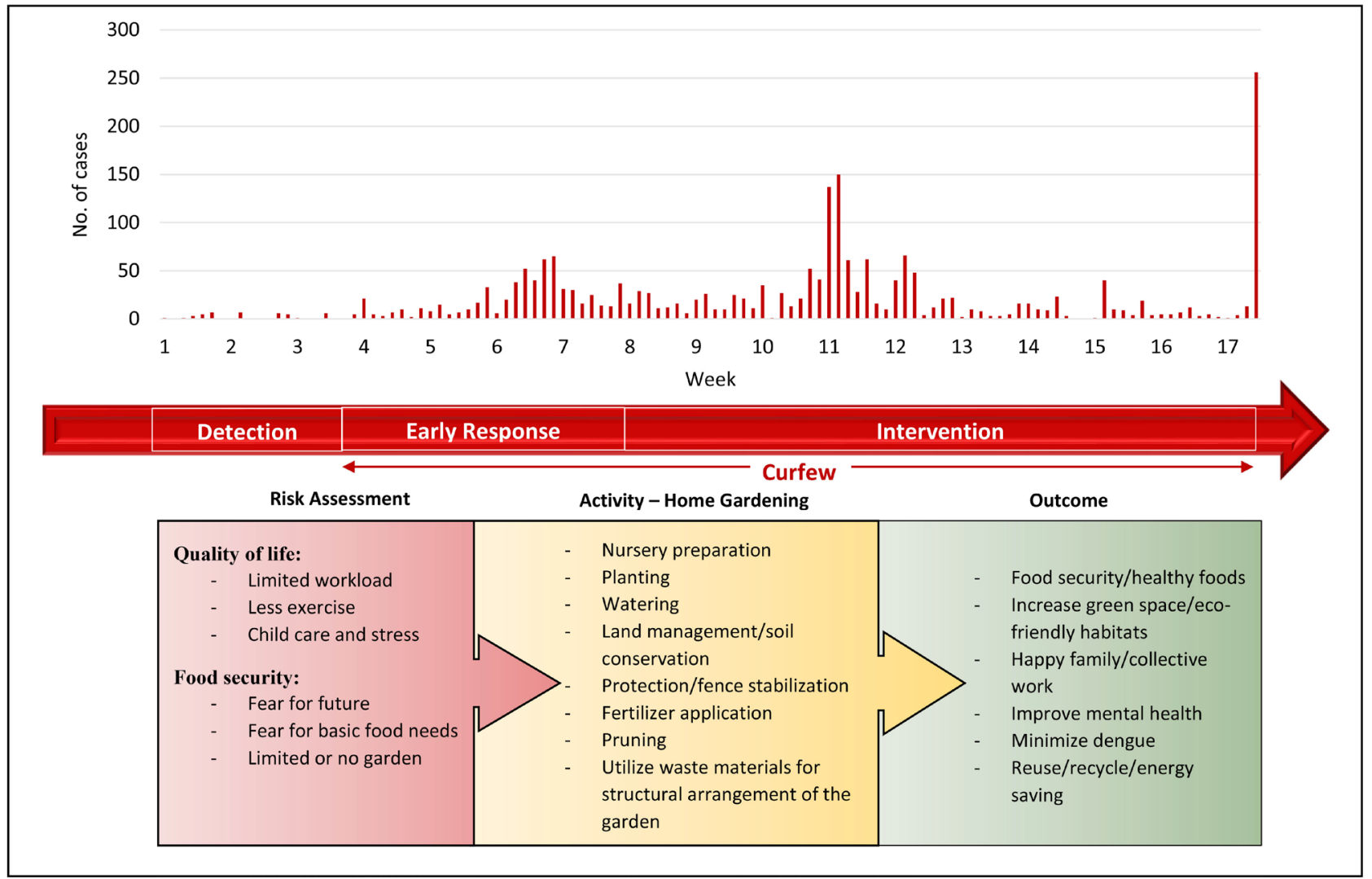

Figure 2. Conceptual framework of the study.

highlights the grids placed for questionnaire data collection. Questionnaire was a self-designed one which was particularly considered to reveal the solutions for risks arisen with the COVID-19 pandemic considering the different activities governing towards development of urban green space, assurance of food security, and quality of life. As it is shown in the conceptual framework, outcomes received through home gardening pertain with the responses obtained for different parameters. Seeds for cultivation, fertilizer application, chemical application, family labor (gender wise and contributed member wise), paid labor, and harvest sharing related data were obtained corresponding to situation before the pandemic and situation during the pandemic. Time allocated for gardening per week, land management strategies, expenses to buy vegetables per week, expenses to buy fruits per week, personal satisfaction with home gardening related data were obtained comparatively to situation before the pandemic. It could rely on the questionnaire survey data as the responses were obtained for recent time period real life experience. Also field observations were further validated the data obtained at the time. Data feeding and analysis were supported through IBM SPSS Statistics 25 software.

\section{Results and Discussion}

There is no doubt, home gardening can provide many more benefits to urban dwellers as well as to improve the natural space in urban areas. Requirement of 
home gardening came to the platform and was triggered with the COVID-19 pandemic situation. The topic was popular via telecommunication media exclusively with the adversity of the pandemic.

Given that, movements and triggers of home gardening were identified through different aspects. As it shows in Figure 3, major depicts are the tendency towards homemade seeds for cultivation, sharing and supports obtained through extension services during the COVID-19 pandemic situation. As per the perception of the respondents, growing plants from homemade seeds have benefitted for urban dwellers as they can go multi variety of cultivate types rather than purchasing. Even they have obtained good knowledge about seed selection and seeding techniques by the support of YouTube videos as well as through the help of elderly persons in the home.

As Figure 4 portrays, direct seeding and transplanting are the prominent seeding techniques used by the respondents.

It is notable, people have not used chemical fertilizers for their gardens in terms of fruits and vegetable cultivation even before the pandemic situation. They have gone towards homemade fertilizer application and application of shared fertilizer from neighbors or supportive parties during the pandemic. When the situation compared to the before status, people have given importance for fertilizer application; which means their requirement to obtain good product from their cultivation. Figure 5 illustrates the context. As it shows in Figure 6, there is no chemical application for gardening even before or during the pandemic.

The study was pictured the labor inputs for the home gardening. Figure 7 illustrates that home gardening has been women dominant activity in the previous situation. There is no doubt, male members may busy with their jobs and therefore they may not interested in gardening. However, real need of gardening for household food security came with the COVID-19 pandemic situation. In the one hand, there were no products to buy and in the other hand the safety issues. That's why both men and women members have been enthusiastically engaged in home
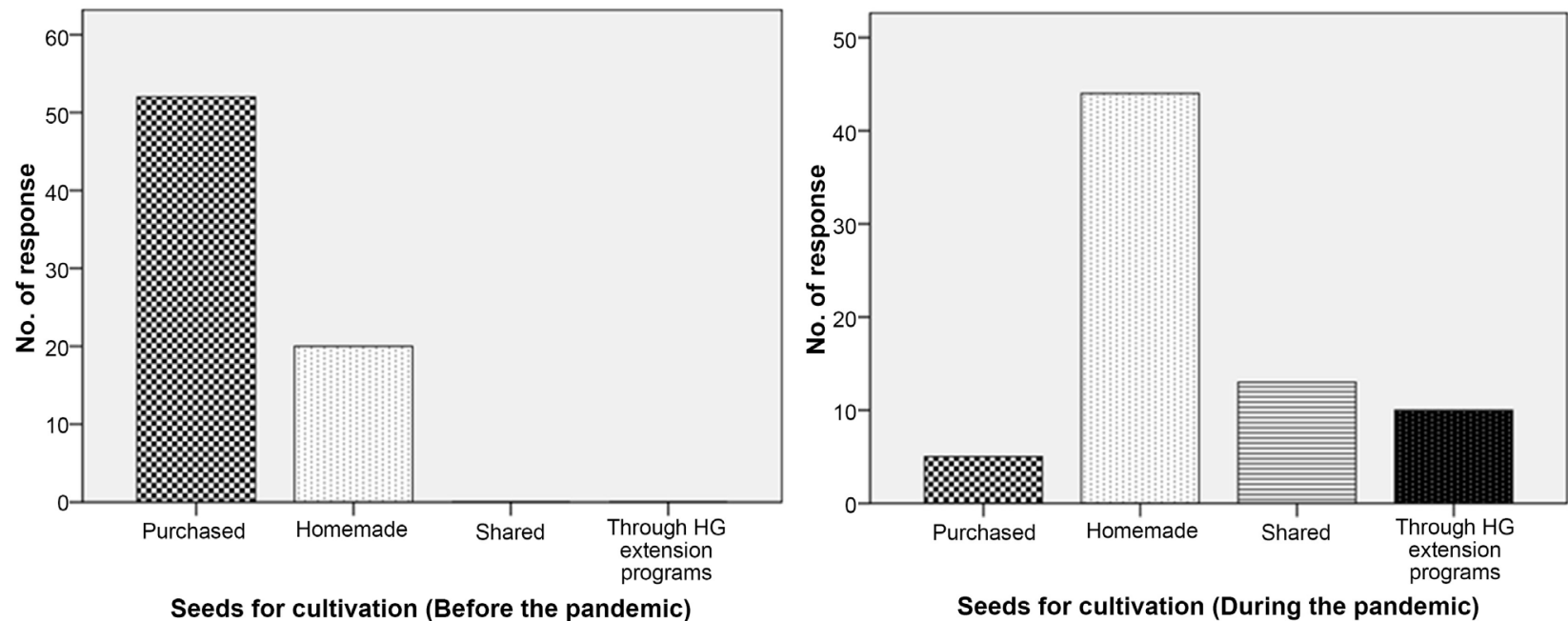

Figure 3. Seeds obtained for cultivation in before and during the pandemic. 

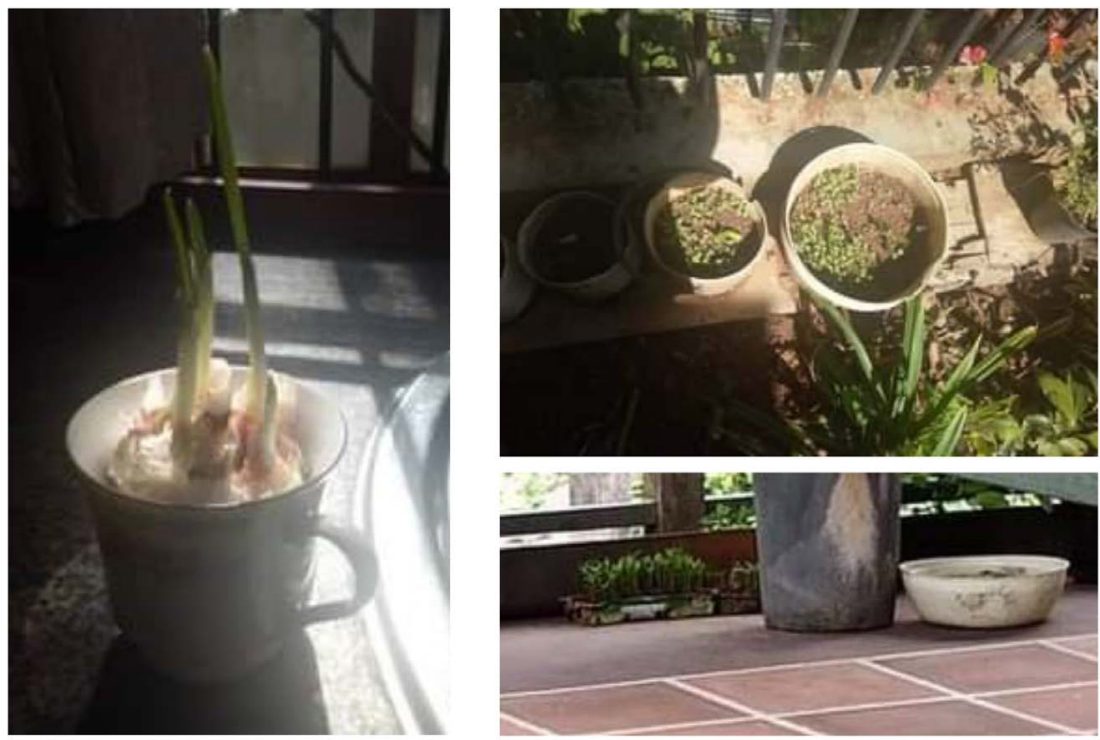

Figure 4. Seeding methods used during the pandemic.

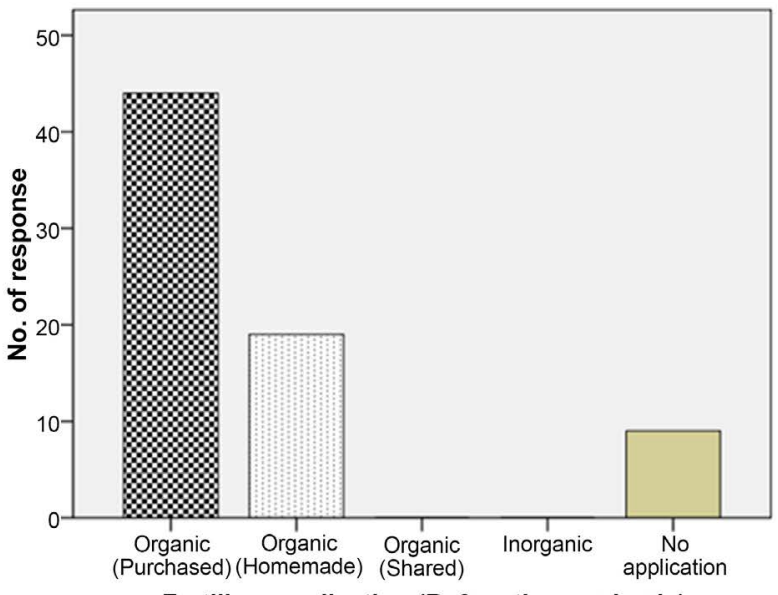

Fertilizer application (Before the pandemic)

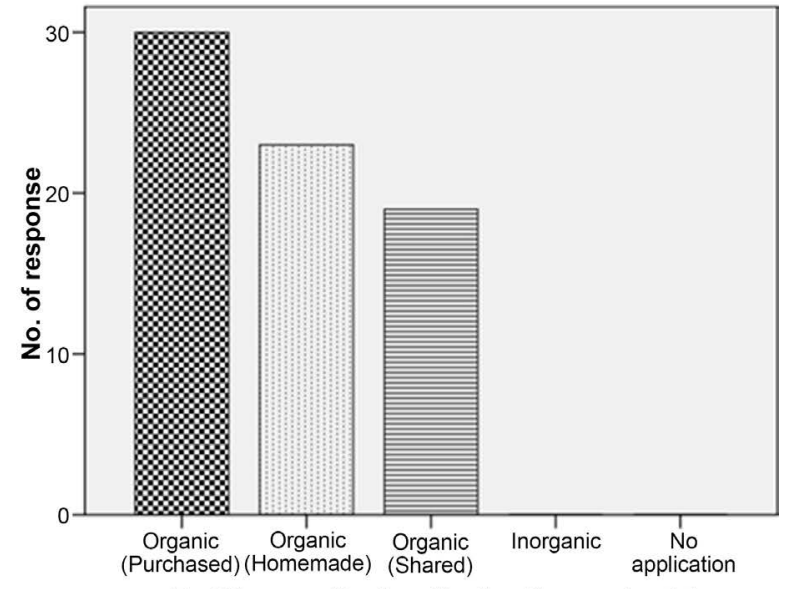

Fertilizer application (During the pandemic)

Figure 5. Fertilizer application for gardening in before and during the pandemic.

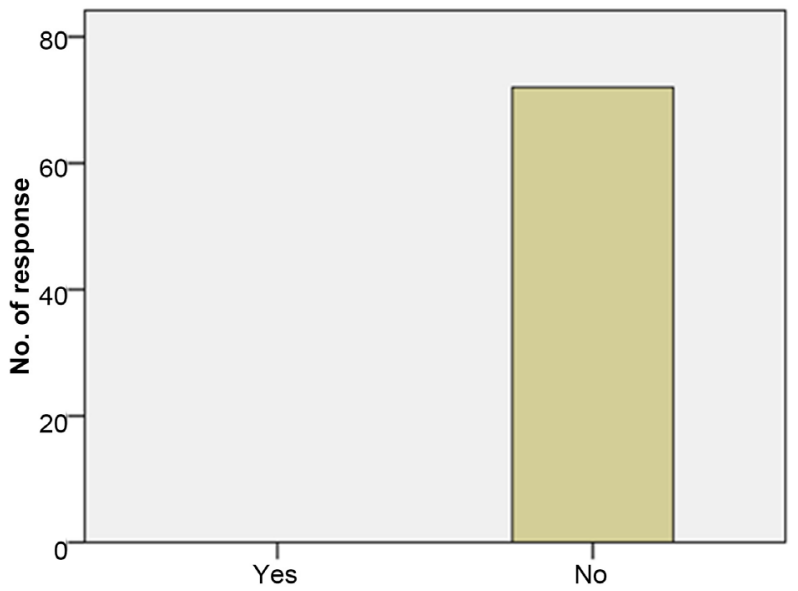

Chemical application (Before the pandemic)

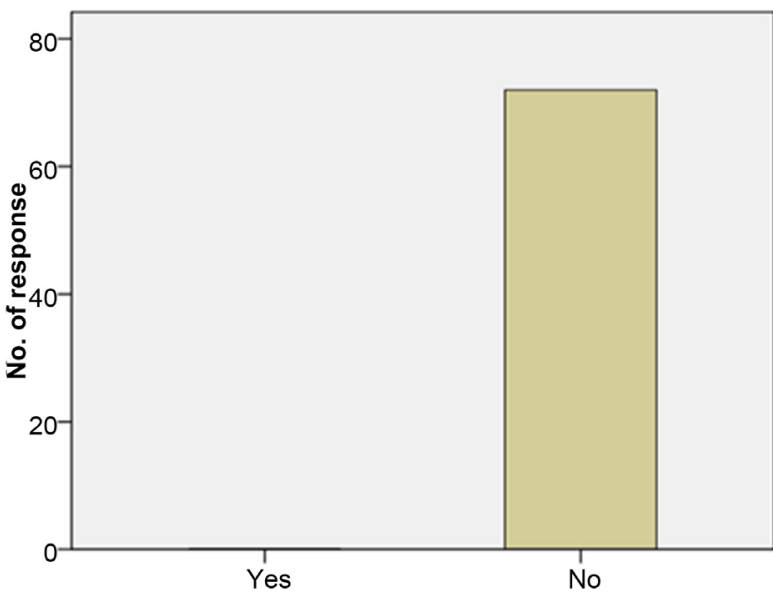

Chemical application (During the pandemic)

Figure 6. Chemical application for gardening in before and during the pandemic. 

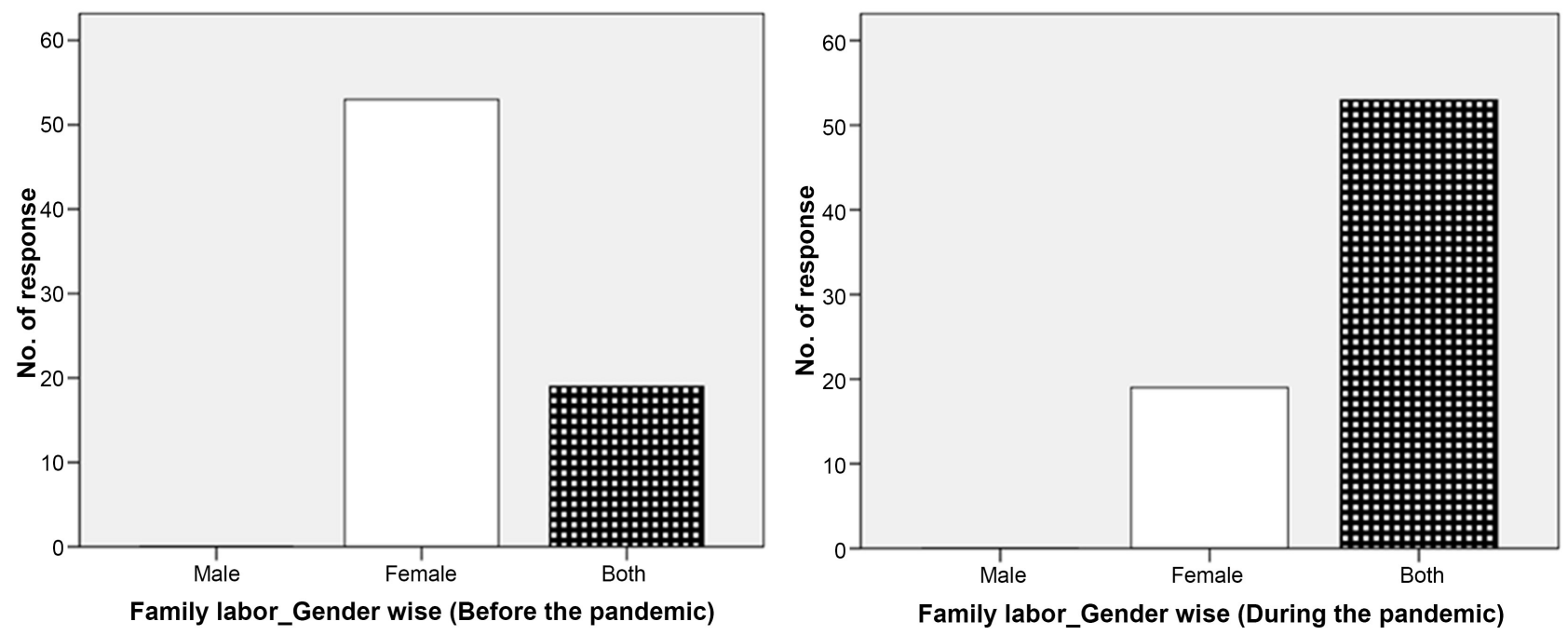

Figure 7. Family labor (gender wise) for gardening in before and during the pandemic.

gardening. Figure 8 shows that, even contribution to gardening has not limited to the elder women and men and whole family has contributed to gardening. It is also about the development of harmonization among family members and a good experience for children as well.

Figure 9 illustrates that, even they have not used paid labor for gardening functions. It is exactly due to social distancing. By the way, they have attained benefits with gardening under minimum or no additional cost. The time allocated for gardening clarify the situation further as all the respondents mentioned that they spend more time in home gardening compared to the situation before pandemic. Figure 10 clues for that with the data analysis in SPSS.

Time spend in home garden was dynamic between about 15 minutes up to 2 hours per day as per the responses through the survey. As Figure 11 illustrates, almost around 50 respondents have responded that as they were more concerned about land management during the pandemic time. Soil erosion mitigation methods using blocks and stones were revealed through the survey as well as through the field observations.

Instead of that, they have a concern about pruning and safety assurance methods like fences. Fences are more importantly needed them to avoid animal disturbances especially to protect garden from wild pigs. As per the respondents, animal damages from wild pigs and monkeys have disturbed for home gardening during harvesting time. In some cases, they were unable to get the harvest due to this issue. Insect damages also appear to be a threat for the home gardening due to there is no chemical pesticide application in home gardening. In such cases, protected net houses and traditional $\mathrm{kem}$ remedies would be effective.

Utilize waste materials for structural arrangement of the garden also attain important aspect in this study. As Figure 12 shows, plastic bottles, polythene bags, and gutters have been used to grow plants directing waste management with reusing. These are easy to use even for indoor gardening by avoiding space limitations in urban areas. 

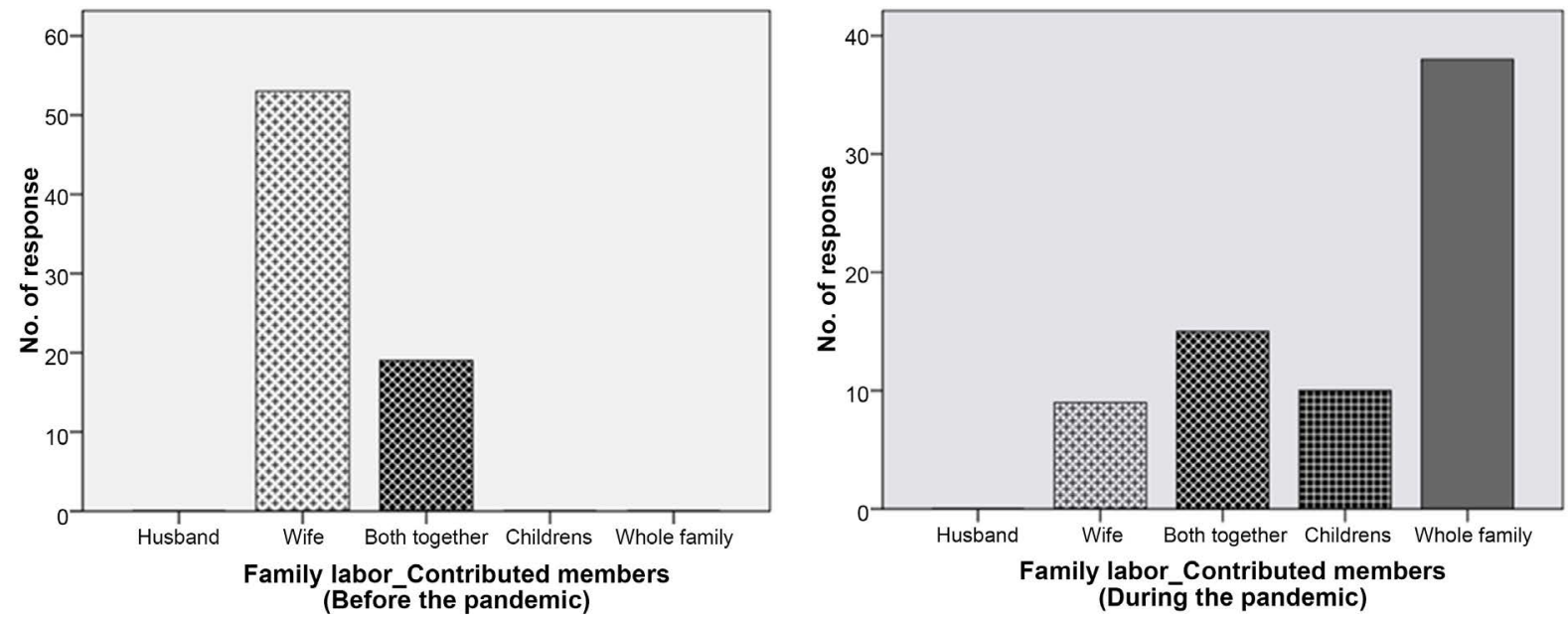

Figure 8. Family labor (contributed members wise) for gardening in before and during the pandemic.
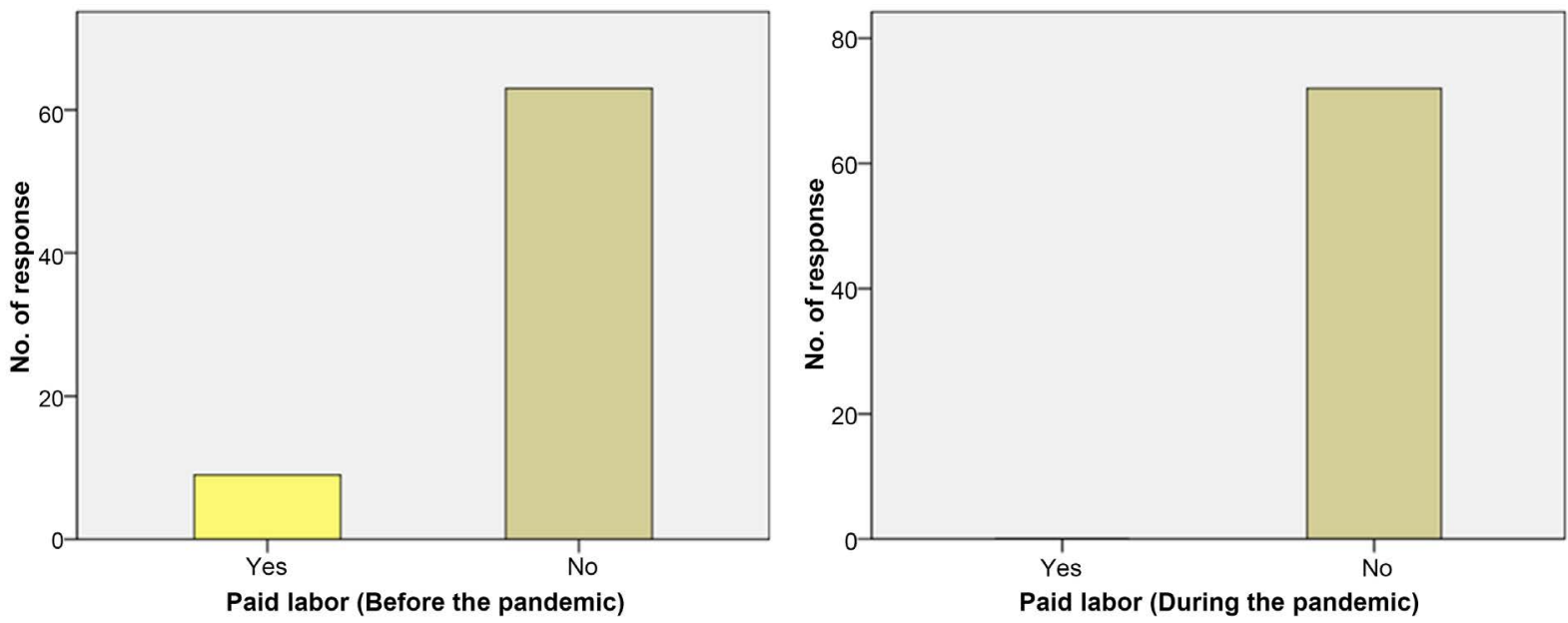

Figure 9. Paid labor for gardening in before and during the pandemic.

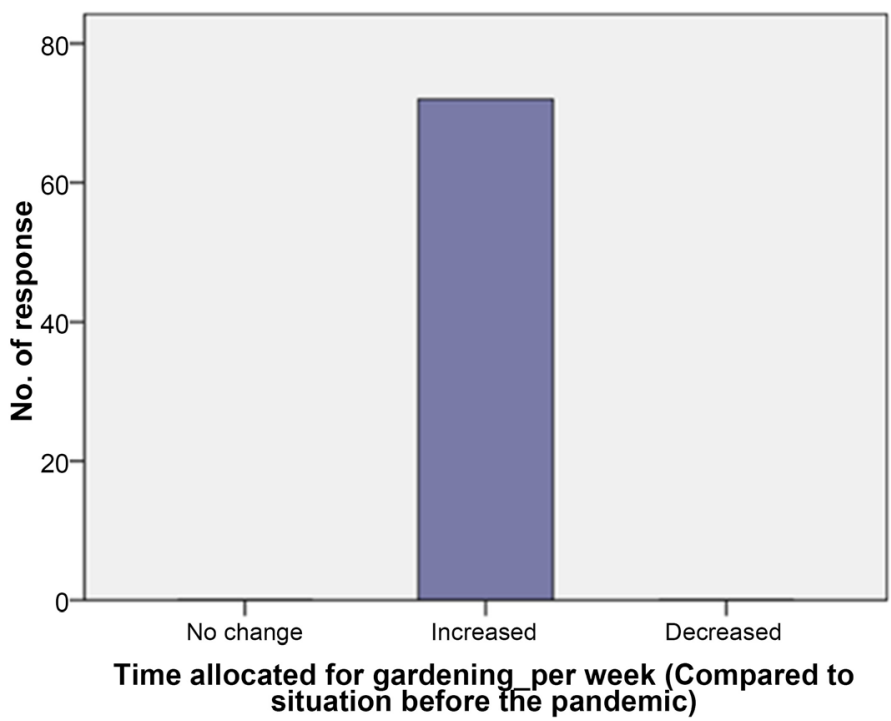

Figure 10. Time allocated for gardening (per week) compared to situation before the pandemic. 


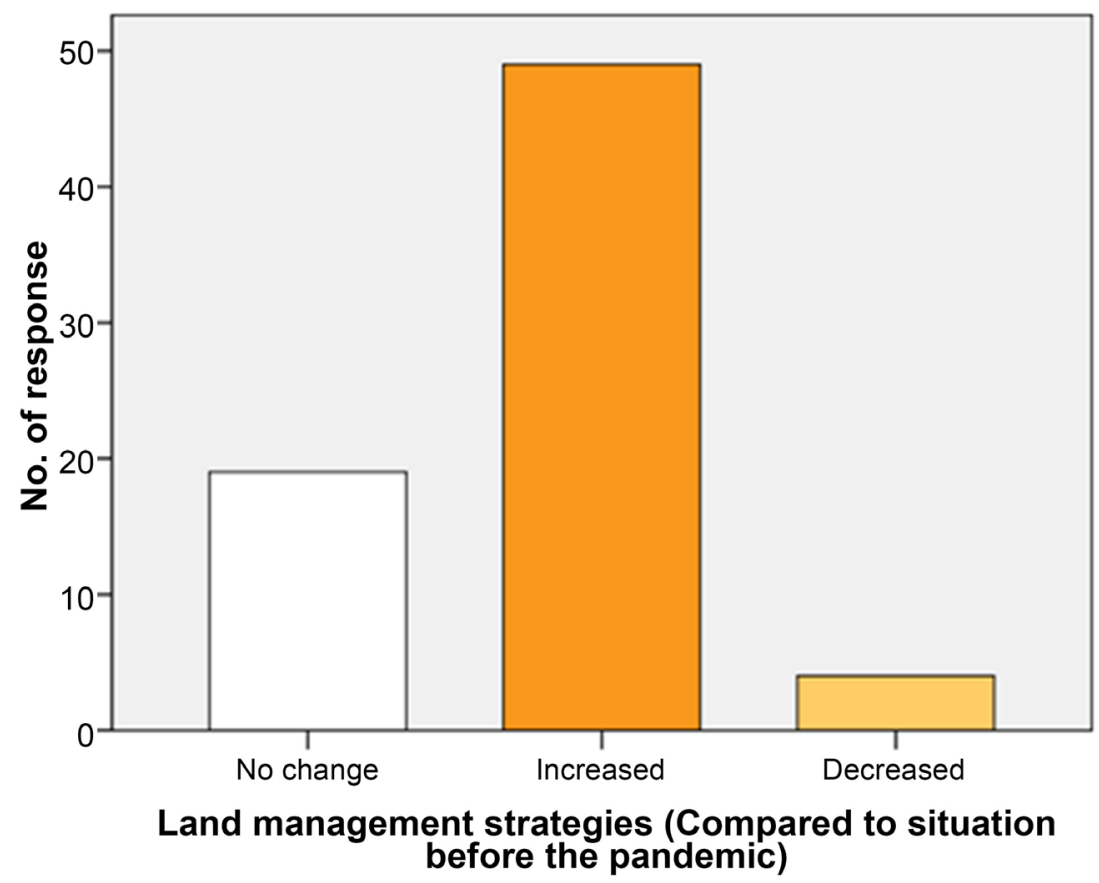

Figure 11. Land management strategies for gardening compared to situation before the pandemic.
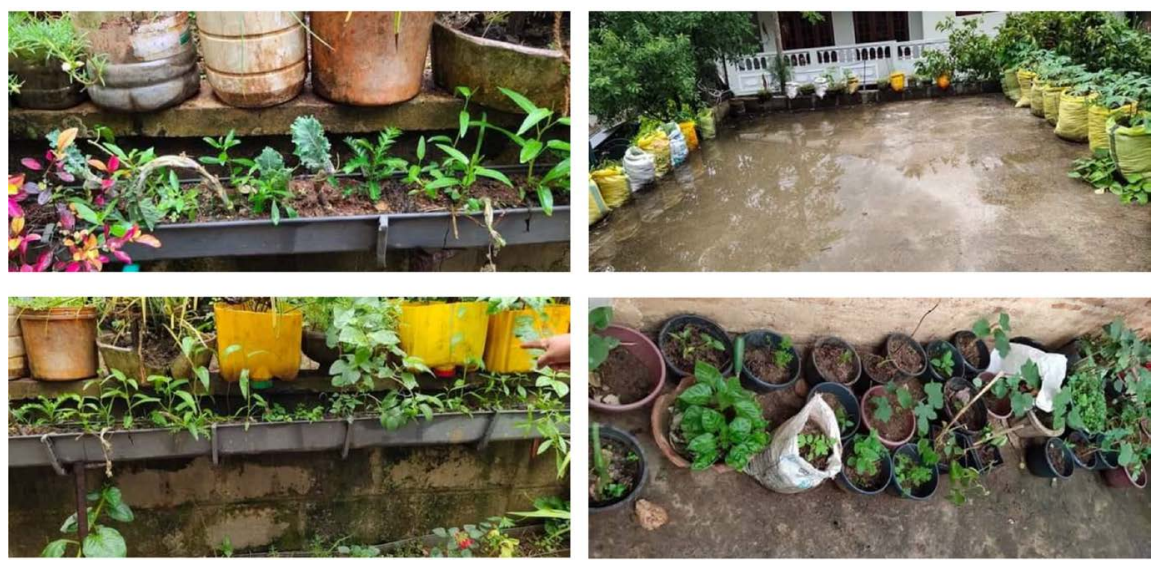

Figure 12. Utilize waste materials for structural arrangement of the home garden.

As it is shown in Figure 13, harvest sharing has been promoted during the pandemic situation. It is not about the household food security and is intrinsically helpful to promote social mobility.

As Figure 14 illustrates, home gardening has supported for food security while giving economic benefits as well. Accordingly, expenses to buy fruits have reduced during the pandemic period and is not due to the harvest of the homemade products. Because, respondents were revealed that as they were discouraged to buy fruits due to health security concerns. However, homemade vegetable products have given benefits to them to cutoff cost for market products. Capsicum, bitter-gourd, brinjal, tomato, pumpkin, spinach, asparagus, amaranth, bean, okra, and chili are the common types of vegetables they cultivate. 

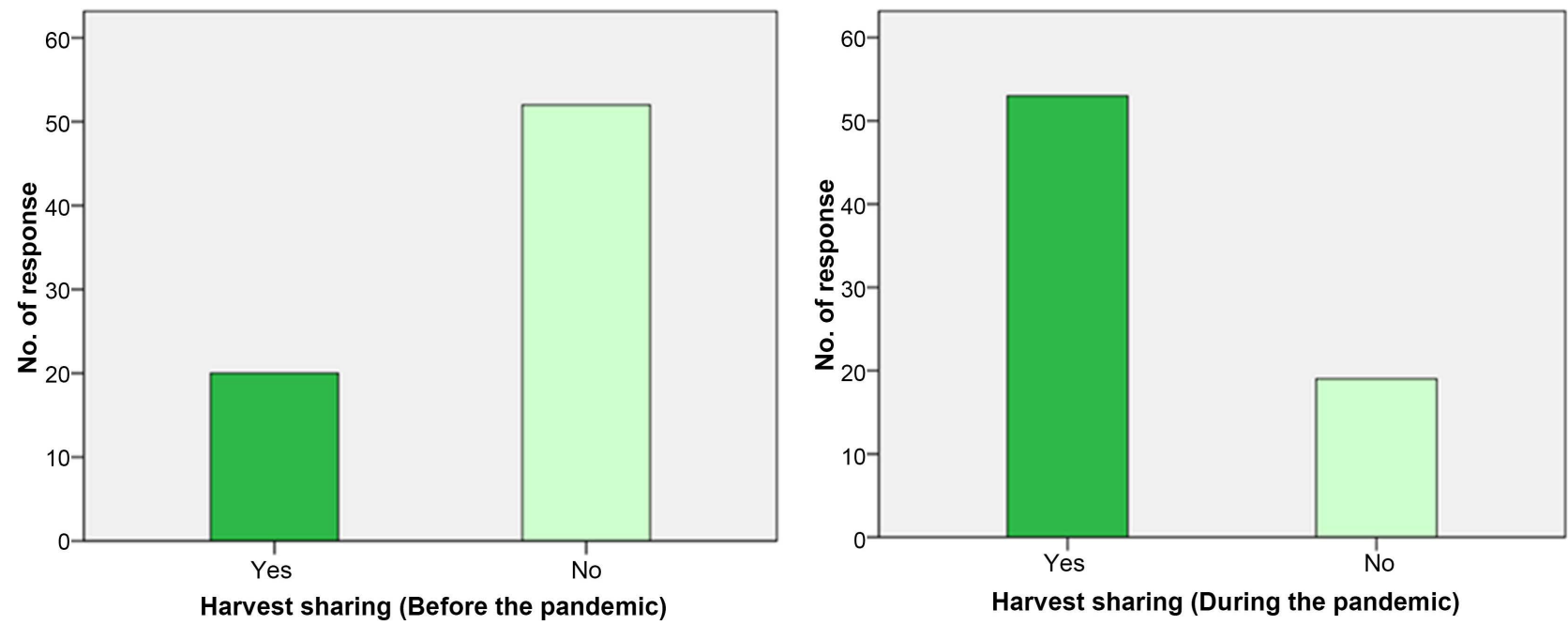

Figure 13. Harvest sharing in before and during the pandemic.
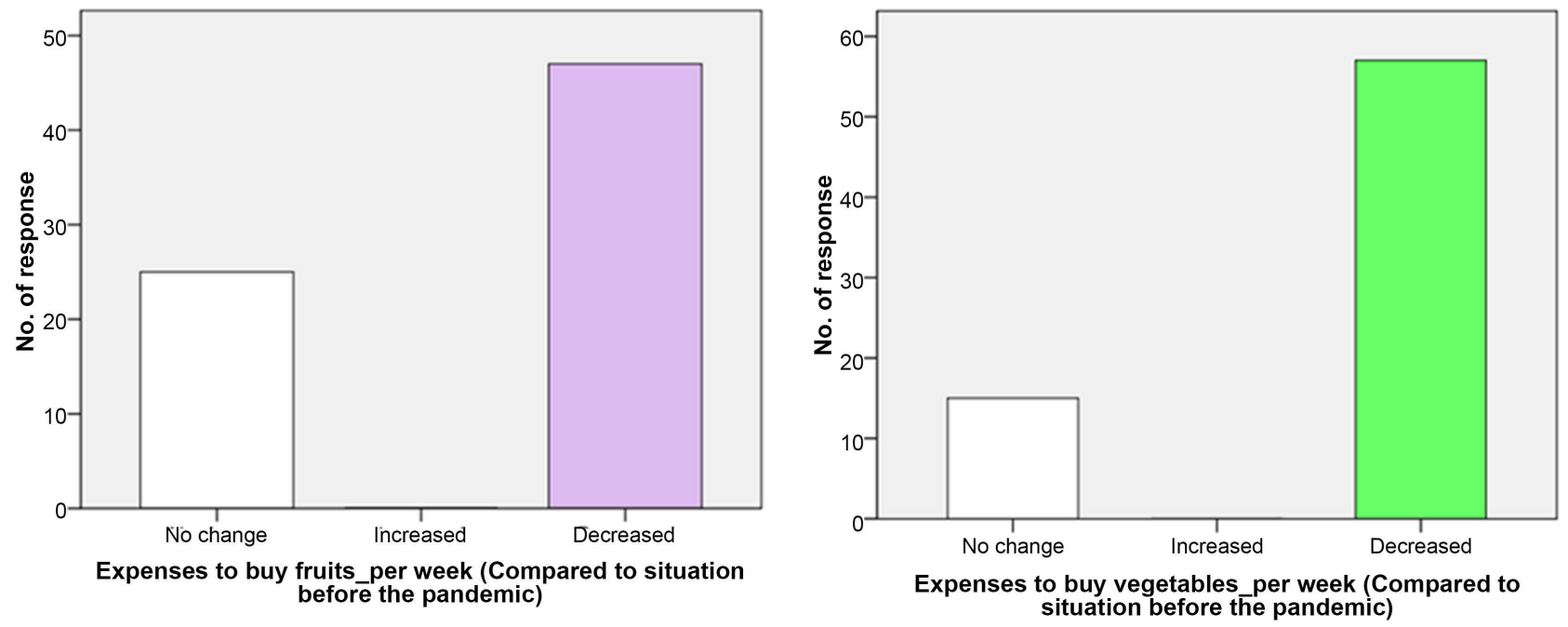

Figure 14. Expenses to buy fruits and vegetables in before and during the pandemic.

\section{Conclusion and Recommendation}

It is notable, respondents' perception regard home gardening is highlighted in the aspect of social well-being and mental health in all three satisfaction levels. None of them mentioned as they don't satisfy with gardening. As the study highlighted over different parameters, stress release, collective work, family harmonization, exercise, sharing and social cohesion, knowledge and experience, and healthy foods can be recognized as the outcomes received in the aspect of social well-being and mental health. Greening, aesthetic beauty, land management and erosion control, waste management and clean environment are the highlighted outcomes which can be directed toward environmental quality. Cutoff the costs for buying foods can be put into the aspect of economic benefits. It is more important in the pandemic situation when there is a shortage of food supply and safety issues. As it illustrates through Figure 15, social well-being and mental health has obtained the highest proportion among both highly and moderately sa- 


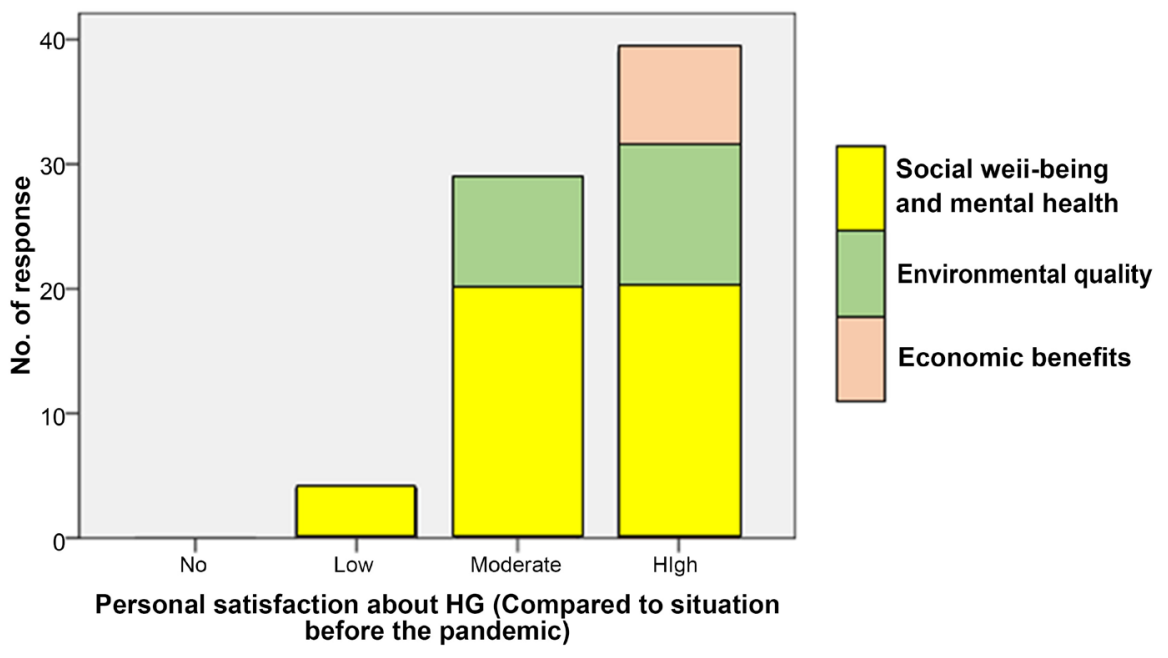

Figure 15. Personal satisfaction about home gardening compared to situation before the pandemic.

tisfied sections. The second aspect they revealed is about environmental quality. Economic benefits are highlighted only among the highly satisfied group.

Conversely, there are barriers over the urban home gardening in the study area. Especially to obtain desired harvest with the gardening. In such cases, fences, protecting net houses, and traditional kem remedies can be suggested to overcome the issue. Another aspect is the lack of knowledge about seed selection, proper land management up to harvesting. Insect damages are mostly due to no tolerance capacity of the plants and causing low productivity. Other issue is the lack of support from extension services to promote home gardening in urban areas. Because it might be a challenge for lack of attention towards market products. However, this is to fill the healthy balance diet by adding leaves and to favor food with homemade spices. In this scenario, it can specify and promote crops for home gardens. It would be beneficial for urban dwellers in case of any emergency situation. Government, agriculturalists, academicians, NGO's, and most importantly urban dwellers or beneficiaries can come into a common platform to promote home gardening in urban areas. Thus, large scale agricultural sector would not be affected and can promote and supply demanding products for local and international market.

Findings obtained through the study can be recognized as background knowledge base in order to promote home gardening by understanding deficiencies and efficiencies. Given that, this preliminary study would be helpful for policy makers to get base level understanding through perceptions of general public/beneficiaries about the requirement of home gardening in an outbreak situation.

\section{Conflicts of Interest}

The authors declare no conflicts of interest regarding the publication of this paper. 


\section{References}

Dissanayake, D. M. L. (2016). Challenges for Urban Ecology by Rapid Urbanization and Global Environmental Change. Shanghai: Holiday Inn.

Dissanayake, D. M. S. L. B., Morimoto, T., Ranagalage, M., \& Murayama, Y. (2019). Land-Use/Land-Cover Changes and Their Impact on Surface Urban Heat Islands: Case Study of Kandy City, Sri Lanka. Climate, 7, 99. https://doi.org/10.3390/cli7080099

Dissanayake, L., \& Dilini, M. M. G. S. (2020). Structure and Processes of Home Gardens in Urban Landscape: Case of Galle, Kandy and Jaffna Cities in Sri Lanka. In J. Breuste, M. Artmann, C. Ioja, \& S. Qureshi (Eds.) Making Green Cities-Concepts, Challenges and Practice, Cities and Nature, (pp. 154-166). Cham: Springer International Publishing.

Fernando, T., \& Gunawardena, A. (2016). Remote Sensing Based Approach for Identification of Degrade Prone Lands in Kandy District. NSF Research Summit.

Kunhamu, T. K. (2013). Tropical Homegardens. Agroforestry-Theory and Practice. In A. J. Raj, \& S. B. Lal (Eds.) (pp. 365-375). Jodhpur: Scientific Publishers.

Niñez, V. K. (1987). Household Gardens: Theoretical and Policy Considerations. Agricultural Systems, 23, 167-186. https://doi.org/10.1016/0308-521X(87)90064-3

Premasiri, H. D. S., Samarasinghe, I. H. K., \& Lakmali, K. M. N. (2012). Population EXposure Risk Assessment to Air Pollution in Kandy City Area. Colombo: Environmental Division, National Building Research Organization.

http://www.nbro.gov.lk/images/content_image/publications/symposia/2010/populatio $\underline{\text { n_exposure_risk_assessment.pdf }}$

Pushpakumara, D. K. N. G., Marambe, B., Silva, G. L. L. P., Weerahewa, J., \& Punyawardena, B. V. R. (2012). A Review of Research on Homegardens in Sri Lanka: The Status, Importance and Future Perspective. Tropical Agriculturist, 160, 55-118.

Torres, E. B. (1988). Socioeconomic Aspects of Backyard Gardening in the Philippines. Philippines University, Department of Agricultural Economics.

Wikipedia (2020). Kandy. https://en.wikipedia.org/wiki/Kandy

World Population Review (2020). Population of Cities in Sri Lanka. https://worldpopulationreview.com/countries/cities/sri-lanka/ 